\title{
COVID 19 reflection/experience on teaching-learning and assessment: story of anatomy teachers in India
}

\author{
Apurba Patra $^{1} \cdot$ Kumar Satish Ravi ${ }^{2} \cdot$ Priti Chaudhary $^{1}$
}

Received: 20 July 2020 / Accepted: 18 September 2020 / Published online: 26 September 2020

(c) Japanese Association of Anatomists 2020

As the world is suffering from an ongoing and serious pandemic, I felt it necessary to comment, from the perspective of a teacher, on the impact this pandemic has had and is having on anatomical education (Franchi 2020) in India. My concerns are basically about the implications it might have on the future of current anatomy students. So, here I wish to present some of my experiences on this matter. Readers must be aware of the fact that the outbreak of the novel coronavirus began in Wuhan, China, in late December 2019 (Zhu 2020). The World Health Organization named the disease caused by this severe acute respiratory syndrome coronavirus 2 (SARS-CoV-2) as COVID-19 on 11th February (WHO 2020a), and subsequently labelled it a pandemic on 11th March (WHO 2020b). On 2nd April, the number of cases reported worldwide crossed 1 million, with 205 countries and territories affected (Worldometer 2020). In India, country-wide lockdown was imposed on 23rd March, and since then the majority of universities and medical colleges had suspended face to face teaching, forcing teachers and students to move to online distance learning for an indefinite period. However, the teaching-learning of anatomy with cadaveric dissection has become almost non-existent in most medical schools due to the lack of the number of corpses compared with the growing number of students. In India, the scenario is completely different from European countries; till date, most of the Indian medical schools use cadaveric dissections as the prime source of teaching anatomy. So, the COVID-19 pandemic situation has hit us hard and created a lot of ruckus in medical teaching. Specifically, if we talk about teaching anatomy, the magnitude of its impact is many folds, because our curriculum is practical work based, which is not possible at the present. Although medical teachers are

Apurba Patra

apurba.cnmc03@gmail.com

1 All India Institute of Medical Sciences, Bathinda, Punjab, India

2 All India Institute of Medical Sciences, Rishikesh, India trying their best to teach students using different online platforms available, practical work is missing. Being a teacher in anatomy, initially it was really impossible for us to teach the subject in this pandemic period. In regular days, we used to do dissection of a particular region in the morning session so that students can see and feel the anatomical structures. On the same afternoon, we used to conduct lecture on the same topic. However all of a sudden, we have entered into a virtual world of teaching and learning after a country-wide lockdown was announced. Neither could we do dissection nor take lectures in a lecture theatre in front of the students. The situation was really extraordinary and no one had any clue how to continue the teaching-learning process. Initially, few faculty started with sending ppts and YouTube links to make the process fruitful, but the students did not find it useful and there was lot of confusion regarding the method of teaching to be adopted. Few institutes started with online teaching using platforms such as Zoom, Webex and Google Meet. We also thought of doing the same in our institution (All India Institute of Medical Sciences, Bathinda), but before starting we thought of taking students' opinion regarding such method of teaching. After getting their views, we found that most of the students were not in favour of online platforms and the reasons cited were network issues, as most of our students were from either rural or suburban areas. Now, we were left with only one feasible option: that was making video lectures with recorded narration. Initially, it was the department of anatomy that started such a method of teaching and luckily our students found it very innovative and useful. We started getting a huge response from our students. Side by side, we started online discussions using Google Classroom, followed by online assessment like quiz competition. The students were really happy with this method. It was like a gush of fresh air for all of us in the middle of the COVID-19 pandemic situation. Gradually, other departments acknowledged our efforts and few started doing the same. Despite the advances in technology, we believe that cadaveric dissection is the ideal and the most 
effective method of teaching anatomy (Ghosh 2017), as it is one of the methods of training hands and fingers for future surgical procedures on living human beings (Ajita and Singh 2007). Government of India, Ministry of Health and Family Welfare, recently have issued guidelines of dead body management in view of COVID-19 pandemic understanding the significance of dead body (Ravi 2020). Now when I am writing our story, it is already 3 months in this virtual world of anatomy and we all are eagerly waiting to go back to the D-hall 'where death laughs to teach the living'.

Funding This study was not funded.

\section{Compliance with ethical standards}

Conflict of interest The authors declare that they have no conflict of interest.

\section{References}

Ajita R, Singh YI (2007) Body donation and its relevance in anatomy learning - a review. J AnatSoc India 56:44-47

Franchi T (2020) The impact of the Covid-19 pandemic on current anatomy education and future careers: a student's perspective. Anat Sci Educ 13:309-312
Ghosh SK (2017) Cadaveric dissection as an educational tool for anatomical sciences in the 21st century. Anat Sci Educ 10:286-299

Ravi KS (2020) Dead body management in times of Covid-19 and its potential impact on the availability of cadavers for medical education in India. Anat Sci Educ. https://doi.org/10.1002/ase.1962

WHO (2020) World Health Organization. WHO Director-General's Remarks at the Media Briefing on 2019-nCoV on 11 February 2020. World Health Organization, Geneva, Switzerland. https:// www.who.int/dg/speeches/detail/who-director-general-s-remar ks-at-the-media-briefing-on-2019-ncov-on-11-february-2020. Accessed 14 July 2020

WHO (2020) World Health Organization. WHO Director-General's Opening Remarks at the Media Briefing on COVID-19-11 March 2020. World Health Organization, Geneva, Switzerland. https://www.who.int/dg/speeches/detail/who-director-general-sopening-remarks-at-the-media-briefing-on-covid-19---11-march -2020. Accessed 14 July 2020

Worldometer (2020) Worldometers.Info. Covid-19 Coronavirus Pandemic. Worldometer Information Technology \& Services, Geneva, Switzerland. https://www.worldometers.info/coronaviru s/. Accessed 14 July 2020

Zhu N, Zhang D, Wang W et al (2020) China novel coronavirus investigating and research team. A novel coronavirus from patients with pneumonia in China, 2019. N Engl J Med 382:727-733

Publisher's Note Springer Nature remains neutral with regard to jurisdictional claims in published maps and institutional affiliations. 